\section{Weakening link to colorectal cancer?}

he catalytic $\gamma$-subunit of the enzyme phosphatidylinositol-3-OH kinase $(\mathrm{PI}(3) \mathrm{K} \gamma)$ relays signals from $\mathrm{G}$ protein-coupled receptors at the cell membrane and mediates leukocyte responses to chemokines and chemoattractants ${ }^{1-3}$. Sasaki et al. ${ }^{4}$ report that mice that cannot produce $\mathrm{PI}(3) \mathrm{K} \gamma$ have a high incidence of colorectal carcinomas, causing weight loss and premature death. However, $\mathrm{PI}(3) \mathrm{K} \gamma$-null mouse strains have been independently generated in three other laboratories; none of these mice developed tumours and their weight and lifespan were normal. This casts coubt on the idea that loss of functional $\mathrm{PI}(3) \mathrm{K} \gamma$ leads directly to transformation of colon epithelial cells and tumour progression.

Disrupting signalling by chemokine receptors has been considered as a strategy to fight chronic inflammatory disease. Signals from these receptors are integrated by $\mathrm{PI}(3) \mathrm{K}^{5,6}$, whose crystal structure $\mathrm{e}^{7}$ and inhibitor interactions ${ }^{8}$ are understood in detail, paving the way to rapid therapeutic exploitation of $\mathrm{PI}(3) \mathrm{K} \gamma$ as a drug target. But promising research was interrupted by the claim of Sasaki et al. ${ }^{4}$ that loss of functional $\mathrm{PI}(3) \mathrm{K} \gamma$ causes colon cancer in mice.

Sasaki et al. ${ }^{4}$ base their conclusions on the fact that their $\mathrm{PI}(3) \mathrm{K} \gamma$-null mouse strain rapidly developed colorectal carcinomas. Using total colon and mucosal samples, they detected $\mathrm{PI}(3) \mathrm{K} \gamma$ in colon tissue but not in murine or human colorectal adenocarcinomas, inferring that the loss of $\mathrm{PI}(3) \mathrm{K} \gamma$ was crucial to the transformation process in epithelial cells.

The murine $\mathrm{PI}(3) \mathrm{K} \gamma$ gene was independently inactivated by four groups, including ourselves ${ }^{1-3}$ and B.L. et al. (unpublished observations), using four different strategies (Fig. 1a), all of which confirmed that this enzyme is important for transmission of inflammatory signals. In our studies, however, mice lacking $\mathrm{PI}(3) \mathrm{K} \gamma$ did not develop tumours, or succumb to weight loss and premature death (Fig. 1b). Analysis of tissue biopsies from more than $100 \mathrm{PI}(3) \mathrm{K} \gamma$-null mice at various ages and of both sexes from two genetic backgrounds (129/Sv inbred and
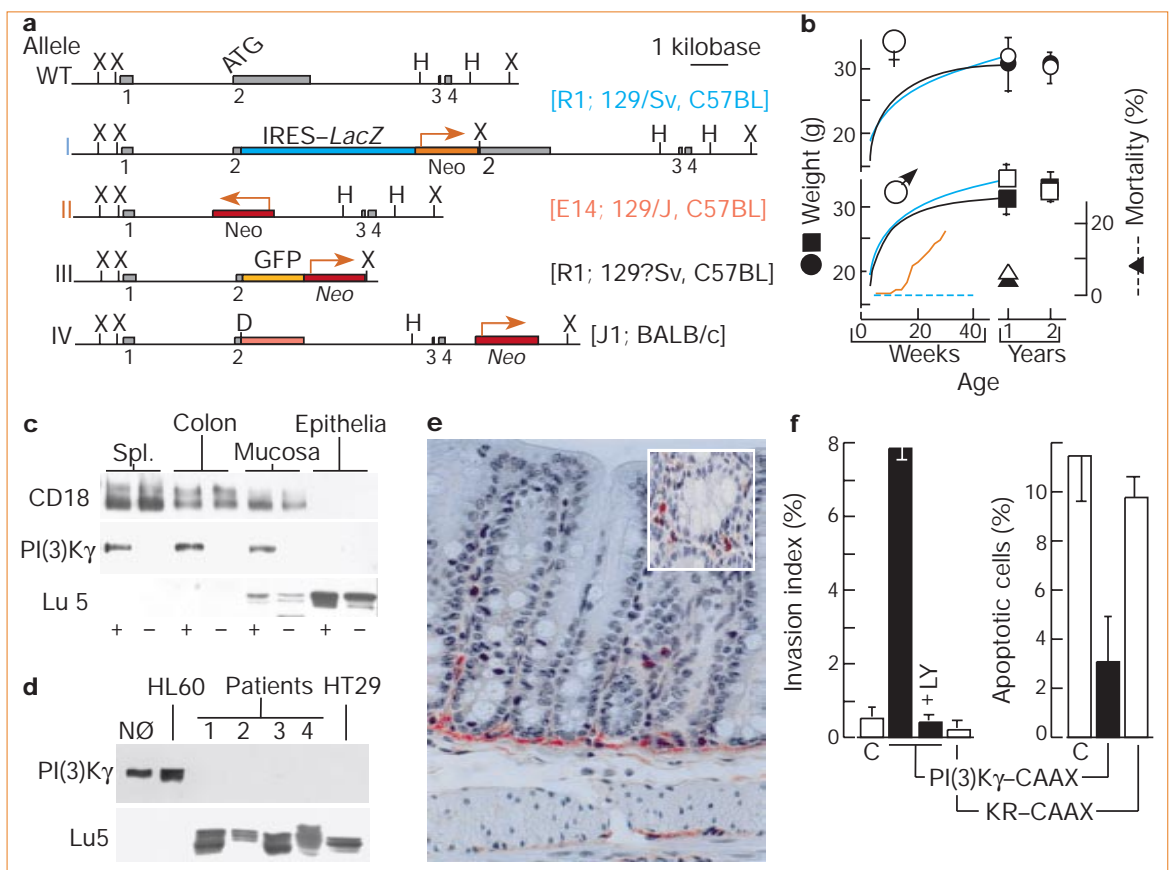

Figure 1 Gene targeting and expression of phosphatidylinositol-3-OH kinase $\gamma$-subunit (PI(3)K $\gamma$ ). a, The wild-type PI(3)K $\gamma$ allele (WT) was targeted using four strategies. Allele I: interception ${ }^{1}$ of exon 2 (embryonic stem cells and mouse strains indicated; for details of the PI(3)K $\gamma$ gene, see ref. 9); allele II: deletion of exon 2, as carried out by Sasaki et al. 2,4 direction of transcription of Neo is opposite to that of PI(3)K $\gamma$; allele III: fusion ${ }^{3}$ of PI(3)K $\gamma$ to green fluorescent protein (GFP) and excision of exon 2; allele IV: start of exon 2 deleted ( 350 base pairs; B.L. et al., unpublished observations). b, Weight and mortality of normal (filled symbols; black lines) and PI(3)K $\gamma^{-1-}$ (allele l: white symbols; blue lines) mice; 465 WT and $602 \mathrm{PI}(3) \mathrm{K} \gamma^{-1-}$ animals; age, 2 yr; sex ratio, 9/10 WT and 34/8 PI(3)K $\gamma^{-1-}$ females/males; mortality from Sasaki et al. ${ }^{4}$ shown in red). c, Murine WT $(+)$ and PI(3)K $\gamma^{-1-}(-)$ splenocytes (spl.), total colon, mechanically sheared mucosa and isolated colon epithelial cells were probed for the leukocyte marker CD18, PI(3)K $\gamma$ (mouse monoclonal anti-PI(3)K $\gamma$, amino-terminal epitope), and the pan-epithelial marker Lu-5. d, Anti-PI(3)K $\gamma$ and Lu-5 western blots of total human cell lysates from neutrophils (NØ), retinoic-acid-differentiated $\mathrm{HL} 60$, primary cultures of normal human colonocytes ${ }^{10}$ from large bowel resected from four patients with diverticulitis, and the HT29-Cl.16E cell line. e, PI(3)K $\gamma$ immunoreactivity (red) in rat colonic mucosa (inset, cross-section of crypt). f, Invasion of collagen gels and serum-withdrawal-induced apoptosis of human colorectal HCT8/S11 cells stably transfected with control vector (C), membrane-targeted PI(3)K $\gamma\left(\mathrm{PI}(3) \mathrm{K} \gamma\right.$-CAAX, black bars ${ }^{11}$ ) or a catalytically inactive mutant (PI(3)K $\gamma(\mathrm{K} 833 \mathrm{R})$ - CAAX; KR-CAAX, white bars). The PI(3)K inhibitor LY294002 (LY) was used at $10 \mu \mathrm{M}$. Further details are available at http://www.unifr.ch/biochem/wymann.
C57BL/6]/129 outbred) showed no malignant transformation (results not shown).

We ther efore re examined the $\mathrm{PI}(3) \mathrm{K} \gamma$ expression pattern reported by Sasaki et al. ${ }^{4}$, and found that $\mathrm{PI}(3) \mathrm{K} \gamma$ signals in colonic mucosa correlate with the presence of leukocytes, as shown by the CD18 marker or by histology, but that $\mathrm{PI}(3) \mathrm{K} \gamma$ is undetectable in normal colonic epithelial cells (positive for the Lu5 cytokeratin marker) from mice, human patients or rats (Fig. 1c-e). We conclude that normal and transformed colonic epithelial cells (such as the HT29 cancer cell line) do not express detectable amounts of $\mathrm{PI}(3) \mathrm{K} \gamma$, making a direct cause-and-effect relationship between loss of $\mathrm{PI}(3) \mathrm{K} \gamma$ and development of colon cancer unlikely.

Invasiveness and growth-factor-independent survival of human colorectal HCT8/S11 tumour cells was promoted by constitutively active, membranetargeted $\mathrm{PI}(3) \mathrm{K} \gamma(\mathrm{PI}(3) \mathrm{K} \gamma$-CAAX), but not by its absence or by stable transfection with catalytically inactive $\mathrm{PI}(3) \mathrm{K} \gamma$ (KR-CAAX; Fig. 1f). This suggests that malignancy is coupled to activated $\mathrm{PI}(3) \mathrm{K}$ and not to its loss.

Our findings are consistent with a lack of tumorigenesis in $\mathrm{PI}(3) \mathrm{K} \gamma$-null strains generated by three out of four strategies. The reproducibility and consistency of the diverging results, however, make it possible that an unknown gene-targeting effect enhances other growth-promoting signals in the PI (3)K $\gamma$-null allele used by Sasaki et al. ${ }^{4}$. Their interesting phenotype therefore needs further investigation, and may eventually reveal an important cause of colon cancer.

M. Barbier*, S. Attoubt, R. Calvez*, M. Laffargue*, A. Jarrył, M. Mareel§, F. Altruda||, C. Gespacht, D. Wuף, B. Lu\#, E. Hirsch\|, M. P. Wymann*

*Institute of Biochemistry, University of Fribourg, 1700 Fribourg, Switzerland

e-mail: matthiaspaul.Wymann@UniFR.ch †IN SERM U 482, H ôpital Saint-Antoine, 75571 Paris 12, France

‡IN SERM U 539, H ôtel-Dieu, 44035 Nantes, France §Laboratory of Experimental Cancerology, Ghent University, De Pintelaan 185, 9000 Ghent, Belgium ||Dipartimento di Genetica, Biologia e Biochimica,

Università di Torino, 10126 Torino, Italy

ID epartment of Genetics and D evelopmental

Biology, University of Connecticut, Farmington,

Connecticut 06030, USA

\#Children's H ospital, H arvard M edical School,

Boston, M assachusetts 02115, USA

1. Hirsch, E. et al. Science 287, 1049-1053 (2000).

2. Sasaki, T. et al. Science 287, 1040-1046 (2000).

3. Li, Z. et al. Science 287, 1046-1049 (2000).

4. Sasaki, T. et al. Nature 406, 897-902 (2000).

5. Wymann, M. P., Sozzani, S., Altruda, F., M antovani, A. \& Hirsch, E. Immunol. Today 21, 260-264 (2000).

6. Rickert, P., Weiner, O. D., Wang, F., Bourne, H. R. \& Servant, G. Trends Cell Biol. 10, 466-473 (2000).

7. Walker, E. H., Perisic, O., Ried, C., Stephens, L. \& Williams, R. L. Nature 402, 313-320 (1999).

8. Walker, H. E. et al. Mol. Cell 6, 909-919 (2000).

9. Hirsch, E. et al. Gene 256, 69-81 (2000).

10. Branka, J. E. et al. Gastroenterology 112, 1887-1894 (1997).

11. Bondeva, T. et al. Science 282, 293-296 (1998). 